\title{
CULTURA MATERIAL ESCOLAR: O MOBILIARIO EM DISCUSSÃO
}

\author{
Gustavo Rugoni de Sousa ${ }^{1}$
}

Tendo como delimitação temporal o período final do século XIX e começo do século XX, este trabalho possui como objetivo fomentar discussões e ampliar compreensões sobre o mobiliário presente em instituições escolares. Para tanto, as análises aqui desenvolvidas estão pautadas pela noção de cultura material escolar e levam em consideração que o período selecionado para análises está diretamente ligado à expansão da escola de massas e obrigatória, que por sua vez articula-se à expansão industrial.No que diz respeito ao provimento material de instituições escolares, pesquisas até então desenvolvidas têm demonstrado a existência de relações entre indústria, escola e Estado e reforçam a relevância e a necessidade de ampliar as investigações que problematizem o mobiliário escolar não apenas como um produto fabricado pela indústria, mas que o compreendam também como um artefato construído socialmente por meio de diferentes saberes (ALCÂNTARA, 2014).

Dados obtidos por autores como Nóvoa e Schriewer (2000) e divulgados em estudos do campo da História da Educação têm colaborado para a construção de um panorama que demonstra que, a partir do final do século XVIII, passa a ganhar força um projeto de escolarização em que os objetos são entendidos como centrais, sendo indicados como fundamentais para a prática pedagógica.Por meio desses trabalhos identifica-seum conjunto de evidências que demonstram a importância da circulação de ideias no processo de difusão de um determinado modelo escolar que passou a ser apropriado em diferentes países e contribuiu para mudanças no perfil dos artefatos desejados.Nesse compasso, foi possível perceber que o Estado, além de um forte comprador, foi promotor de políticas e ideias que incentivaram a expansão de um modelo escolar. Como exemplo, pode-se citar a

\footnotetext{
${ }^{1}$ Professor do Departamento de Metodologia do Ensino da Universidade Federal de Santa Catarina (MEN/UFSC) e doutorando da linha de pesquisa História e Historiografia da Educação do Programa de Pós-Graduação em Educação da Universidade do Estado de Santa Catarina (PPGE/UDESC), possui como orientadora a professora doutora Vera Lucia Gaspar da Silva e é membro do grupo de pesquisa "Objetos da Escola". E-mail: gustavorugoni@gmail.com
} 
elaboração de prescrições e a implantação da obrigatoriedade de ensino, as quais contribuíram para o fortalecimento da escola como um nicho de mercado atraente para a indústria.

As leituras desses trabalhos bem como as inserções em arquivos contribuíram para que se adotasse uma perspectiva que considera o mobiliário como uma tecnologia que apresenta o resultado de políticas, concepções e relações que são construídas em seu entorno, carregando, portanto, sentidos diversos consigo e sendo capazes de alterar ou influenciar rotinas e práticas de professores e alunos. Dessa forma, tecnologias como o lápis, a tesoura, livros, borrachas e a carteira, que, no imaginário social contemporâneo muitas vezes são naturalizadas como objetos que sempre fizeram parte do cenário escolar, nem sempre compuseram esse espaço, mas foram adentrando a partir de intencionalidades pedagógicas, médicas e econômicas. Desse modo, destaca-se que o provimento material escolar e as relações mantidas em torno do processo de idealização e fabricação de tecnologias resultam em implicações e mudanças na cultura escolar.

Levando essas questões em consideração, para a realização desta pesquisa optou-se por realizar o levantamento de informações e referenciais acerca do processo de idealização, fabricação e comercialização do mobiliário escolar, tendo como objetivos: (i) localizar e mapear produções que tivessem como foco o mobiliário escolar; (ii) avançar nas pesquisas em arquivos que possuam informações acerca do setor industrial, como, por exemplo, juntas comerciais e acervos de empresas, os quais podem fornecernotas fiscais, contratos de compra e venda e catálogos; (iii) desenvolver uma reflexão que pudesse auxiliar na identificação de movimentos que percorrem a organização escolar em torno do provimento material, buscando problematizar alterações que foram realizadas no mobiliário, como e por quais motivos ocorria a escolha de determinados materiais, assim como das indústrias que seriam responsáveis por fornecê-los. Destaca-se que os dados localizados e analisados a partir dos objetivos acima referidos subsidiaram a escrita do presente trabalho.

Dessa forma, com base nas investigações realizadasem pesquisa de mestrado já concluída, a qual resultou na publicação da dissertação intitulada $D a$ indústria à escola: relações da fábrica Móveis CIMO com o mercado escolar (19121954),percebe-se a escola como bojo de diversos investimentos, principalmente a partir de mudanças nas percepções sobre a importância da infância para a criança, 
o que reverberou em um conjunto de alterações no espaço da escola e em um aumento do número de objetos escolares produzidos por uma indústria em ascensão, que, a partir da Revolução Industrial, passa a buscar novos mercados para comercializar seus produtos. Nesse sentido, chama-se atenção para o processo de internacionalização de ideais educativas, para a realização das Exposições Universais e para o crescente papel do Estado na sociedade, que impulsionaram a comercialização de artefatos e contribuíram para a idealização de novos produtos, bem como para o crescimento de indústrias e para as descobertas de novos mercados.

Cabe ressaltar que devido a diferentes culturas políticas e a fatores de ordem econômica, por exemplo, os modelos de escolas implementados, assim como os objetos idealizados podem ter sofrido alterações e apresentarem-se de maneiras distintas. No entanto, as pesquisas vêm demonstrando que mesmo com "adaptações locais", existem muitos aspectos que se assemelham, provavelmente devido à circulação de ideias, a qual foi impulsionada também pelo circuito das Exposições Universais.

Conforme indica Dittrich (2013), comitivas nacionais eram formadas para que seus representantes pudessem aprender novos conhecimentos e técnicas, para que fossem em busca dos inventos e dasmetodologias de ensino presentes nas Exposições Universais, os quais deveriam ser adaptados aos respectivos países para diminuir déficits quando comparados às nações consideradas na "vanguarda do progresso". No caso brasileiro, por exemplo, o livro O império do Brasil na Exposição Universal de1867 destaca a importância dada pelo governo imperial à organização e financiamento de uma comitiva para participar da Exposição, uma vez que esse espaço era reconhecido como essencial para o conhecimento de outras culturas e também para a internacionalização do país. O interesse era que a partir dessa participação o Brasil pudesse também institucionalizar práticas consideradas como modernas, visando assim o desenvolvimento nacional.

Nesse mesmo trabalho de Dittrich (2013) também é possível identificar a importância e a configuração que as sessões escolares passaram a ter nas Exposições. De acordo com o autor, esses espaços apresentavam as configurações físicas das instituições de ensino, fotografias, livros, manuais, mobílias e objetos pedagógicos, que variavam desde "canetas a máquinas de calcular e quadros murais" (p. 215). Além dos artefatos escolares, eram difundidos nesses espaços os 
considerados modernos métodos de ensino e trabalhos de alunos utilizados a fim de comprovar o sucesso de tais metodologias.

Com relação ao perfil de mobiliário apresentado nas Exposições, 0 trabalho de Alcântara (2014) apresenta uma importante contribuição, pois a autora discorre acerca de diversas carteiras escolares, as quais tinham recebido um conjunto de investimentos de educadores, médicos e industriais que procuravam adequar seu design e tecnologias aos preceitos modernos de ensino. Assim, esse trabalho, somado a outras produções do campo da História da Educação como as de Lawn (2005), Meda (2015) e Kuhlmann Júnior (2001), forneceu elementos que possibilitaram perceber que as novas tecnologias e adaptações no mobiliário presente na escola passaram a expressar, ainda que indiretamente, uma das facetas da modernidade, uma vez que esse apresentava o que existia de "mais moderno" e estava apoiado na ciência e na racionalidade, as quais eram indicadas como as bases dessa nova sociedade.

Dentre os discursos que contribuíram para alterações no mobiliário escolar destacam-se os estudos em torno da higiene, os quais defendiam que estes artefatos não poderiam simplesmente acomodar os estudantes.Diferentemente, o mobiliário deveria ser tomado como um objeto capaz de formar condutas e práticas nas crianças. Para tanto, os investimentos estiveram concentrados na idealização de móveis adequados a preceitos médicos, buscando garantir assim a saúde das crianças e professores. Como exemplo, pode-se destacar a preocupação dos catálogos das empresas analisadas ${ }^{2} e$ de prescrições em documentos oficiais em indicar as distâncias consideradas corretas entre o banco e a mesa da carteira escolar, bem como a utilização de tecnologias que pudessem favorecer o conforto da coluna do estudante, mantendo assim uma postura adequada para a prática da leitura e escrita.

Bencostta (2013) fornece elementos que ajudam a compreender a importância alcançada pela indústria que, em conjunto com arquitetos e designers, médicos e educadores, elaboraram e participaram ativamente na idealização de

\footnotetext{
${ }^{2}$ Grupo de catálogos localizados em diferentes acervos e países: Coleção Paulo Bourroul, disponível na Biblioteca da Faculdade de Educação da USP, São Paulo/Brasil; acervo do Arquivo Histórico Municipal de Rio Negrinho, Santa Catarina/Brasil; acervo do Museu Pedagógico José Pedro Varela; catálogos da francesa Maison Deyrolle e dos Estados Unidos. Assim, mapearam-se fábricas: Móveis CIMO/Brasil, Geo. M. Hammer\&Co./Inglaterra, A. Lickroth\& Cie./Alemanha, The Columbia School/Estados Unidos, e Maison Deyrolle/França. Destaca-se que os catálogos internacionais foram localizados e fotografados por Vera Lucia Gaspar da Silva durante atividades de estágio pós-doutoral que contou com apoio financeiro do CNPq.
} 
para modernizar as instituições escolares. Acompanhando as transformações e experiências dos discursos pedagógicos, os artefatos fabricados passaram a responder também às preocupações relacionadas ao bem-estar dos alunos e ao movimento higienista, discussões que vinham sendo debatidas, principalmente a partir do final do século XIX e que, a indústria, para atender ao nicho do mercado escolar, passou a incorporar em seus produtos.

Ao localizar e analisar catálogos de empresas do setor de móveis situadas em diferentes países (Brasil, Estado Unidos, França, Inglaterra, Alemanha) ${ }^{3}$, bem como notas fiscais e relatórios provenientes de indústrias e instituições escolares, identifica-se que há um aumento do número de artefatos idealizados e comercializados para as escolas, de tal modo que se pode localizar o surgimento de diferentes modelos de carteiras escolares, quadros-negros, museus escolares, escrivaninhas, poltronas e cadeiras. As novas tecnologias e adaptações utilizadas para a construção desses artefatos ganharam destaque nesses documentos e passaram a expressar, ainda que indiretamente, uma das facetas da modernidade, pois representavam o que existia de "mais moderno" e estavam apoiados na ciência e na racionalidade, as quais eram indicadas como as bases dessa nova sociedade.

Entre os catálogos analisados, todas as fábricas, com exceção da Móveis CIMO, indicavam em suas capas - utilizando menções escritas e/ou imagens - que fabricavam móveis para atender ao mercado escolar. Essas indicações poderiam facilitar a identificação pelos consumidores que se interessassem em adquirir os produtos. No caso da empresa estadunidense Columbia School, chama atenção a preocupação em vincular seus produtos aos preceitos higienistas do período. Primeiramente porque a capa apresenta uma imagem com três carteiras perfeitamente ajustadas às diferentes alturas dos alunos, o que demonstra que a empresa buscava divulgar a ideia de que seus mobiliários poderiam se ajustar aos corpos dos estudantes. Para ressaltar a mensagem dessa imagem, a frase "Comfort, adjustability, individuality, durability", em destaque no documento, remete o mobiliário fabricado pela Columbia School à ideia de um artefato confortável, de alta durabilidade, com assentos individuais e passíveis de ajustes.

\footnotetext{
${ }^{3}$ De acordo com informações presentes nos catálogos, esses foram produzidos, respectivamente, nos anos: Móveis CIMO - Brasil (entre 1932 e 1944); The Columbia School - Estados Unidos (1912); Maison Deyrolle - França (1924); Geo. M. Hammer\&Co. - Inglaterra (1893); A. Lickroth\& Cie Alemanha (1887).
} 
No interior desses catálogos localiza-se ainda uma série de produtos fabricados pelas empresas, como carteiras, escrivaninhas, quadros-negros, poltronas, cadeiras, armários-museus, sofás, globos terrestres, cestos de lixo, canetas, balanças, réguas, apagadores, entre outros. Embora situadas no setor moveleiro, algumas firmas não se restringiam apenas a fabricar móveis, uma vez que também se especializaram na fabricação de outros objetos. Para apresentar os produtos aos seus consumidores, os catálogos foram elaborados com imagens e textos, que tinham como objetivo fornecer definições técnicas dos produtos, dimensões, valores e, em alguns mobiliários, informações que destacam os diferenciais de seus modelos e suas soluções para a escola, como o quadro-negro da Mayson Deyrolle, o qual apresenta partituras para que os alunos pudessem completar as notas musicais.

Além disso, as empresas indicavam que faziam uso de matérias-primas que favorecessem a limpeza e tecnologias que facilitassem a organização dos documentos, como gavetas com repartições e diferentes formas de utilização, o que demonstra a presença constante de um discurso pautado em preceitos higiênicos. Para melhor compreender as mudanças ocorridas no mobiliário escolar ao longo da pesquisa, construiu-se uma categoria que pudesse contemplar as relações existentes em torno desse artefato e os diferentes saberes utilizados em seu processo de idealização e fabricação: o "mobiliário em movimento".

Essa categoria indica que a idealização do mobiliário faz parte de uma circulação de saberes provenientes de diferentes campos, tendo como base distintos agentes, entre os quais pode-se citar os médicos educadores, a indústria e o Estado. Os primeiros, defendiam que a escola deveria promover saúde e civilidade também por meio dos seus objetos, os segundos observavam nesse espaço uma oportunidade para comercializar produtos e obter lucros, e o Estado, por sua vez, ao exercer seu papel de comprador, alçou o mercado escolar como um nicho atraente, mas para isso teve também de passar por mudanças burocráticas, administrativas e políticas.

Compreender esse artefato a partir de uma relação com diferentes instituições, como o Estado, a escola e a Indústria tem se configurado uma chave de leitura essencial, uma vez que os aspectos políticos, pedagógicos e econômicos se configuram e marcam o tipo de mobiliário que chega até as escolas. Portanto, reconhece-se a necessidade de se avançar nas reflexões em sentido que se rompa 
com a tendência de que o mobiliário foi alterado em virtude apenas dos preceitos médicos e pedagógicos. Diferentemente, destaca-se que os aspectos econômicos e políticos também estão envolvidos e muitas vezes definiram quais mobílias eram selecionadas e comercializadas.

Por meio das análises efetuadas nota-se a recorrência de um discurso, que era difundido mundialmente e que dava ênfase à necessidade de adequar o mobiliário escolar. Nesse sentido, a pesquisa sobre o mobiliário possibilitou identificá-lo como um dos símbolos da educação moderna, uma vez que ele se localizava no centro dos debates e documentos que tinham como objetivo fazer da escola um aparelho modelar, capaz de instruir as classes menos abastadas e ensinar hábitos e condutas higiênicas.

Ao comparar dados presentes nos diferentes catálogos das empresas, percebe-se que, mesmo utilizando diferentes matérias-primas, há uma convergência entre os modelos de mobiliário apresentados, o que indicia sobre a existência e construção de um padrão de design internacional de mobiliário escolar, o qual passou a ser fabricado e comercializado em diferentes países, influenciado e legitimado por um "modelo ideal" de escola e por indústrias moveleiras que buscavam aumentar seus lucros a partir da comercialização com o Estado.

Cabe ainda destacar que a convergência de um padrão de mobiliário escolar internacional também foi definida por questões que perpassavam o ambiente escolar, uma vez que a utilização da madeira como matéria-prima e a construção de relações políticas entre indústrias e o Estado podiam também definir quais móveis adentravam o espaço escolar, pois, muitas vezes, não existia uma via de mão dupla entre a escolha do mobiliário com questões técnicas, econômicas ou sociais. Diferentemente, as pressões de interesses organizados devem ser levadas em consideração nas análises, pois essas podem alterar as conduções dos negócios públicos. Nesse sentido, Rémond (2003) indica que as escolhas políticas não podem ser entendidas como parte de um sistema homogêneo, como o simples resultado de forças entre categorias, pois essas sofrem influências de múltiplas vozes, as quais muitas vezes estão longe de se compreender. Desse modo, entende-se que esses interesses podem interferir no provimento material das escolas, além de privilegiar fábricas ou regiões pelas decisões políticas do Estado.

\section{REFERÊNCIAS}


ALCÂNTARA, Wiara Rosa Rios. Por uma história econômica da escola: a carteira escolar como vetor de relações (São Paulo, 1874-1914). 2014. 339 f. Tese

(Doutorado em Educação) - Faculdade de Educação, Universidade de São Paulo, São Paulo, 2014.

BENCOSTTA, Marcus Levy. Mobiliário escolar francês e os projetos vanguardistas de Jean Prouvé e André Lurçat na primeira metade do século XX. Revista Educar em Revista, Curitiba, n. 49, jul./set.2013. p. 19-38. Disponível em:

http://ojs.c3sl.ufpr.br/ojs2/index.php/educar/article/view/33289/20942. Acesso em: 8 jun. 2016.

COLUMBIA SCHOOL. Catálogo de móveis escolares da Columbia

SchoolSupplyCo, 1912. Disponível em: Acervo do Museu Pedagógico, São Paulo.

GEO. M. HAMMMER. Illustrated Catalogue School and College Furniture and Educational Apparatus, manufactured by Geo. M. Hammer 7 Co., 370, Strand, London, W.C, 1893. Disponível em: Acervo da Fundação Biblioteca Nacional Brasil.

IMPERIO DO BRAZIL, O Imperio do Brazil na Exposição Universal de 1867 em Paris. Rio de Janeiro: Typographia Universal de Laemmert, 1867. Acervo: Biblioteca do Senado.

INDÚSTRIAS REUNIDAS DE MADEIRAS. Capa do catálogo: fábrica de cadeiras e carteiras escolares, installações para theatros, cinemas, bars e restaurantes. [entre 1932 a 1954b]. Disponível em: Acervo do Arquivo Público de Rio Negrinho, Santa Catarina.

KUHLMANN JÚNIOR, Moysés. As grandes festas didáticas: a educação brasileira e as exposições internacionais (1862-1922). Bragança Paulista - SP: Universidade São Francisco, 2001. 262 p.

LAWN, Martin. Uma pedagogia para o público: o lugar de objetos, observação, produção mecânica e armários-museus. Tradução: David Antonio da Costa; Gustavo Rugoni de Sousa. Revista Linhas, Florianópolis, v. 14, n. 26, jan.jun. 2013, p. 222 243. Disponível em:

http://www.periodicos.udesc.br/index.php/linhas/article/view/1984723814262013222. Acesso em: 08 jun. 2016. doi: 10.5965/1984723814262013222.

LICKROTH \& CIE. Frankenthaler Schulbank-fabrik A. Lickroth\&CieFrankenthal. Berlin, Budapest, Dresden, 1887. Disponível em: Acervo da Fundação Biblioteca Nacional - Brasil.

MAYSON DEYROLLE. Mobilier et MatérielScolaires: Tables, Ardoisage, Bouliers, Compendiums, Tableaux muraux, Physique, Chimie, Histoire naturelle, 1924.

Disponível em: Acervo da Fundação Biblioteca Nacional - Brasil.

MEDA, Juri. A "história material da escola" como fator de desenvolvimento da pesquisa histórico-educativa na Itália. Revista Linhas, Florianópolis, v. 16, n. 30, jan/abril. 2015, p. 07-28. Disponível em: 
http://www.revistas.udesc.br/index.php/linhas/article/view/1984723816302015007/pdf _36. Acesso em: 30 mai. 2016. doi: 10.5965/1984723816302015007.

NÓVOA, A; SCHRIEWER, J. (2000). A difusão mundial da escola. Lisboa: Educa, 2000.

RÉMOND, René. Uma história presente. In: RÉMOND, René. Por uma história política. Rio de Janeiro: Editora FGV, 2003, 13-36. 